УДК 504.064:502.005

\title{
О ЕДИНОЙ МЕТРИКЕ АНТРОПОГЕННОГО ЗАГРЯЗНЕНИЯ ОКРУЖАЮЩЕЙ СРЕДЫ
}

\author{
О. В. Базарский ${ }^{1,2}$, А. А. Курышев ${ }^{2}$ \\ ${ }^{1}$ Военный учебно-научный центр военно-воздушных сил «Военно-воздушная \\ академия имени профессора Н. Е. Жуковского и Ю. А. Гагарина» г. Воронеж \\ ${ }^{2}$ Воронежский государственный университет
}

Поступила в редакцию 28 сентября 2018 г.

\begin{abstract}
Аннотация: рассматриваются существующие подходы к оценке уровня загрязнения окружающей среды. Предлагается методика расчета обобщённого показателя загрязнения окружающей средbl, учитывающая синергетическое взаимодействие загрязняющих веществ. Данный показатель позволяет судить о влиянии загрязнения окружающей среды любым количеством загрязняющих веществ на комфортность проживания населения в различных регионах. Представлены практические примеры его применения.

Ключевые слова: суммарный показатель загрязнения, загрязняющие вещества, синергетическое взаимодействие, придорожная территория, эколого-геологические исследования.
\end{abstract}

\section{ABOUT THE UNIFORM METRICS OF ANTHROPOGENIC ENVIRONMENTAL POLLUTION}

Abstract: In article the existing approaches to assessment of environmental pollution level are considered. The method of environmental pollution the generalized indicator calculation is offered. This index allows to judge influence of the population in various regions accommodation pollutants on comfort environmental by any amount. Practical examples of its application are presented.

Key words: total indicator of pollution, pollutants, synergetic interaction, roadside territory, ecological geology researches.

Существуют два подхода к оценке уровня загрязнения окружающей среды.

1. Описание непосредственного уровня загрязнения окружающей среды, когда коэффициент концентрации $\mathrm{K}_{\mathrm{K}}$ вычисляется как отношение измеренной концентрации загрязняющих веществ (3В) С к фоновой концентрации $\mathrm{C}_{\phi}$, т. е.

$$
K_{K}=\frac{C}{C_{\phi}} .
$$

2. Описание антропогенного уровня загрязнения окружающей среды, влияющего на человека. В этом случае коэффициент концентрации $\mathrm{K}_{\mathrm{i}}$ вычисляется как отношение измеренной концентрации ЗВ к предельно допустимой концентрации (ПДК), т. е.

$$
K_{i}=\frac{C}{\Pi Д К} .
$$

Для первого случая разработан адекватный показатель суммарного загрязнения окружающей среды [1].

$$
Z_{C}=\sum_{K=1}^{n} K_{K}-(n-1),
$$

где $\mathrm{n}$ - число ЗВ. В этом случае для любого числа ЗВ показатель $Z_{c}=1$, при условии, что все $3 \mathrm{~B}$ находятся на фоновых уровнях. При превышении фоновых значений разработана логичная шкала классификации непосредственного уровня загрязнения окружающей среды.

Если показатель $\mathrm{Z}_{\mathrm{c}}$ использовать для описания антропогенного уровня загрязнения окружающей среды, то он может принимать отрицательные значения, и не ясен экологический смысл этого результата, так как теоретически он может стремиться к минус бесконечности. Поэтому в работах [2-4] предлагается при расчете антропогенного показателя $\mathrm{Z}_{\mathrm{c}}$ использовать только коэффициенты $K_{\mathrm{i}}>1$ для случаев повышенного загрязнения среды. Но это можно сделать только для однородно загрязнённой географически ограниченной территории, что сильно сужает возможности его использования.

Для ликвидации указанного недостатка в работе [5] предложен уточненный суммарный показатель загрязнения окружающей среды, вычисляемый по формуле: 


$$
Z_{y}=\sum_{i=1}^{n} K_{i}-\log _{2} n .
$$

Здесь учитываются все загрязняющие вещества как с коэффициентами концентрации $\mathrm{K}_{\mathrm{i}}>1$ так и $\mathrm{K}_{\mathrm{i}} \leq$ 1. Показатель $Z_{y}$ ограничен снизу величиной минус три, и от этого значение до нулевого располагаются градации естественного и техногенного фона. Если

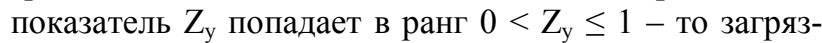
нения окружающей среды классифицируются как «норма». Далее располагаются градации экологического риска, компенсированного и некомпенсированного кризиса, а при $Z_{y}>16$ - бедствия. Недостатком показателя $\mathrm{Z}_{\mathrm{y}}$ как и как и показателя $\mathrm{Z}_{\mathrm{c}}$ является неограниченная сверху зависимость от числа загрязняющих веществ, что привело для выбранного ранжирования к ограничению числа загрязняющих веществ $\mathrm{n} \leq 8$. То есть для использования показателя $\mathrm{Z}_{\mathrm{y}}$ необходимо выбрать восемь приоритетных загрязняющих веществ по величине их коэффициентов концентрации и классов экологической опасности. Показатель $\mathrm{Z}_{\mathrm{y}}$ определяет количество информации в сообщении, полученном при исследовании загрязнения окружающей среды.

Все вышеперечисленные показатели не учитывают синергетического взаимодействия $\mathrm{n}$ загрязняющих веществ, присутствующих в окружающей среде и влияющих на организм человека.

Синергетическими называются кооперативные сфазированные взаимодействия, приводящие либо к усилению, либо к ослаблению суммарного эффекта. В нашем случае все загрязняющие вещества взаимодействуют между собой, и число таких взаимодействий определяется числом сочетаний из $\mathrm{n}$ загрязняющих веществ по два, то есть $C_{n}^{2}$, если не учитывать многоэлементных взаимодействий. Например, для двух загрязняющих веществ имеем их коэффициенты концентрации $\mathrm{K}_{1}$ и $\mathrm{K}_{2}$, и один член взаимодействия $\mathrm{K}_{12}$, для трёх загрязняющих веществ имеем $\mathrm{K}_{1}, \mathrm{~K}_{2}, \mathrm{~K}_{3}$ и $\mathrm{K}_{12}, \mathrm{~K}_{13}, \mathrm{~K}_{23}$ и так далее.

Сфазированное (когерентное) взаимодействие двух величин определяется выражением [6]

$$
Z=K_{1}+K_{2}+2 \sqrt{K_{1} K_{2}} \cos \varphi
$$

где $\cos \varphi-$ фазовый сдвиг между величинами $\mathrm{K}_{1}$ и $\mathrm{K}_{2}$. Если $0 \leq \cos \varphi<\frac{\pi}{2}$, то наблюдается усиление суммарного эффекта, при $\frac{\pi}{2} \leq \cos \varphi<\pi-$ ослабление, а при $\varphi=\frac{\pi}{2}-$ некогерентное аддитивное сложение, то есть $Z=K_{1}+K_{2}$. Фактически $\cos \varphi=r_{12}$, то есть это коэффициент корреляции между величинами $\mathrm{C}_{1}$ и $\mathrm{C}_{2}$, причем $(-1) \leq r_{12} \leq 1$. Тогда

$$
Z=K_{1}+K_{2}+2 \sqrt{K_{1} K_{2}} r_{12} .
$$

Эту формулу можно использовать для описания синергетического взаимодействия загрязняющих веществ в организме человека. Если $r_{12}>0$, то есть в организме человека загрязняющие вещества коррелируют между собой, то их негативное синергетическое влияние усиливается. Реально таких взаимодействием мало, так как иначе человек не смог бы существовать в загрязнённой среде. По-видимому, это случай поступления в организм отравляющих веществ. Если $r_{12}$ $<0$, то негативное синергетическое взаимодействие уменьшается, обеспечивая приспосабливаемость человека к загрязненной окружающей среде. Если $r_{12}=$ 0 , то происходит некогерентное накопление загрязняющих веществ в организме с их прямым суммированием и последующим выведением продуктов метаболизма. По-видимому, это случай долговременного приспособления организма человека к загрязнению окружающей среды большим числом загрязняющих веществ.

Теперь обобщенный показатель антропогенного загрязнения окружающей среды для произвольного числа n ЗВ можно записать следующим образом

$$
Z_{o}=\sum_{i=1}^{n} K_{i} \pm \frac{2 \sum_{C_{n}^{2}} \sqrt{K_{i} K_{j}}}{n} .
$$

Здесь $\sqrt{K_{i} K_{j}}$ - взаимнокорреляционный член, определяемый антропогенными коэффициентами концентрации i-того и ј-того загрязняющих веществ, $C_{n}^{2}$ - суммарное число взаимокорреляционных членов, усредненное по всем взаимодействия, $\overline{r_{i j}}=\frac{1}{n}-$ усредненный коэффициент их взаимной корреляции. При $\mathrm{n} \rightarrow \infty$ получаем случай некогерентного взаимодействия загрязняющих веществ в организме человека $\overline{r_{i j}}=0$. Для одного вещества имеем автокорреляцию, $\overline{r_{11}}=1$, для четырех веществ $\overline{r_{i j}}=0,25$ и т.д. При ограниченном сочетании загрязняющих веществ за счёт приспособленности организма к негативному действию окружающей среды $\overline{r_{i j}}$ отрицателен, и в формуле для показателя $Z_{\text {о }}$ результирующим является знак минус.

Проанализируем поведение показателя $\mathrm{Z}_{\mathrm{o}}$. Показатель $Z_{\text {о }}$ зависит только от величины коэффициентов концентрации загрязняющих веществ $\mathrm{K}_{\mathrm{i}}$ и смешанных коэффициентов $\mathrm{K}_{\mathrm{i}} \mathrm{K}_{\mathrm{j}}$, связанных с числом взаимокоррелирующих веществ. Он не зависит от числа загрязняющих веществ, что принципиально отличает его от известных показателей суммарного загрязнения. Он ограничен снизу, то есть $Z_{\mathrm{o}} \rightarrow 0$ при малых значениях концентраций измеренных загрязняющих веществ. Если принять фоновую концентрацию загрязняющего вещества равную $\frac{\Pi Д К}{8}$, то показатель $\mathrm{Z}_{\mathrm{o}}$, соответ- 
ствующий фоновому уровню равен 0,125 . Если коэффициенты концентрации всех загрязняющих веществ равны единице, то верхний уровень нормы равен единице. Если все $K_{i}=2$, то $Z_{o}=2$; если $K_{i}=3$, то $Z_{o}=3$ и так далее.

То есть независимо от числа загрязняющих веществ получаем следующие градации показателя $\mathrm{Z}_{\mathrm{o}}$. Если $0<Z_{0} \leq 0,125$ классифицируется фоновое состояние окружающей среды. Если $0,125<\mathrm{Z}_{\mathrm{o}} \leq 1-$ норма. Если $1<Z_{\mathrm{o}} \leq 2$ - экологический риск. Если 2 $<Z_{\text {o }} \leq 3$ - компенсируемый экологический кризис. Если $3<Z_{\mathrm{o}} \leq 4-$ некомпенсируемый экологический кризис, если $Z_{o}>4$ - экологическое бедствие. То есть бедствие наступает, когда все загрязняющие вещества, имеющиеся в окружающей среде, превышают ПДК более чем в 4 раза. В этом случае длительное существование человека в такой среде становится невозможным, и часть людей погибает. Остаются люди с генетическими мутациями, приспособившиеся к сильно загрязнённой окружающей среде, которые породят новую популяцию.

Для сравнения антропогенных показателей $\mathrm{Z}_{\mathrm{y}}$ и $\mathrm{Z}_{\mathrm{o}}$ проанализируем загрязнение участка федеральной трассы М4 «Дон» с 464 по 564 км четырьмя приоритетными 3В: свинцом, цинком, медью и кадмием. В 2013 г методом конверты были отобраны пробы приповерхностных отложений с глубины 0-20 см на расстоянии 5 и 10 м от края полотна. В аккредитованной лаборатории были измерены концентрации подвижных форм этих элементов.

Результаты расчетов показателей $\mathrm{Z}_{\mathrm{y}}$ и $\mathrm{Z}_{\mathrm{o}}$ с привязкой к тому или иному рангу загрязнения окружающей среды приведены в табл. 1 .

Видно, что в большинстве точек пробоотбора результаты применения обобщенного показателя дают более жесткую оценку загрязнения окружающей среды. Это связано с тем фактом, что только показа-

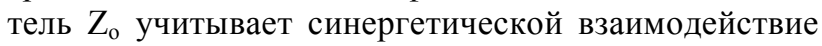

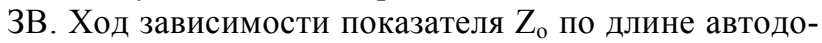
роги дает лучшее совпадение с результатами математического моделирования [7], чем по показателю $\mathrm{Z}_{\mathrm{y}}$, что свидетельствует о более высокой эффективности обобщенного показателя $Z_{\mathrm{o}}$.

Коэффициенты концентрации, уточненный суммарный показатель загрязнения $\left(Z_{y}\right)$ и обобщенный показатель антропогенного загрязнения $\left(Z_{o}\right)$ придорожной территории федеральной трассы M4 «Дон»

\begin{tabular}{|c|c|c|c|c|c|c|c|}
\hline $\mathrm{TM}$ & \multirow{2}{*}{ Год отбора проб } & \multirow{2}{*}{ Расстояние от полотна, м } & \multicolumn{5}{|c|}{ Километры автодороги } \\
\hline $\mathrm{Ki}$ & & & 464 & 489 & 514 & 539 & 564 \\
\hline \multirow{2}{*}{ Свинец } & \multirow{2}{*}{2013} & 5 & 1,1 & 2,0 & 2,1 & 2,2 & 1,8 \\
\hline & & 10 & 0,4 & 0,5 & 0,6 & 1,1 & 0,9 \\
\hline \multirow{2}{*}{ Цинк } & \multirow{2}{*}{2013} & 5 & 1,5 & 1,9 & 1,9 & 2,3 & 1,9 \\
\hline & & 10 & 1,1 & 0,6 & 0,2 & 0,6 & 1,0 \\
\hline \multirow{2}{*}{ Медь } & \multirow{2}{*}{2013} & 5 & 2,6 & 1,4 & 1,8 & 3,9 & 3,0 \\
\hline & & 10 & 2,1 & 1,2 & 1,7 & 3,0 & 2,8 \\
\hline \multirow{2}{*}{ Кадмий } & \multirow{2}{*}{2013} & 5 & 0,2 & 0,1 & 0,2 & 0,2 & 0,2 \\
\hline & & 10 & 0,1 & 0,1 & 0,1 & 0,1 & 0,1 \\
\hline \multirow{4}{*}{$Z_{y}$} & 2013 & 5 & 3,4 & 3,4 & 4 & 6,6 & 4,9 \\
\hline & \multicolumn{2}{|c|}{ Ранг загрязнения ОС } & э.p. & э.p. & к.к. & к.к. & к.к. \\
\hline & 2013 & 10 & 1,7 & 0,4 & 0,6 & 2,8 & 2,8 \\
\hline & \multicolumn{2}{|c|}{ Ранг загрязнения ОС } & $\mathrm{H}$ & $\mathrm{H}$ & $\mathrm{H}$ & э.p. & э.p. \\
\hline \multirow{4}{*}{$Z_{\mathrm{o}}$} & 2013 & 5 & 2,06 & 2,14 & 2,17 & 3,40 & 2,62 \\
\hline & \multicolumn{2}{|c|}{ Ранг загрязнения ОС } & к.к. & к.к. & к.к. & н.к. & к.к. \\
\hline & 2013 & 10 & 1,66 & 0,91 & 1,23 & 2,25 & 2,12 \\
\hline & \multicolumn{2}{|c|}{ Ранг загрязнения ОС } & э.p. & $\mathrm{H}$ & э.p. & к.к. & к.к. \\
\hline
\end{tabular}

Примечание: н. - норма; э.р. - экологический риск; к.к. - компенсируемый кризис; н.к. - некомпенсируемый кризис.

\section{Выводы}

1. Разработан обобщенный показатель антропогенной оценки уровня загрязнения окружающей среды, учитывающий синергетическое взаимодействие загрязняющих веществ.

2. Обобщенный показатель более точно описывает структуру загрязнения придорожной территории федеральной трассы M4 «Дон» с 464 по 564 км, для анализируемого участка которой была построена математическая модель.
3. Гостированный показатель $Z_{c}$ не учитывает антропогенное влияние ЗВ и имеет достаточно ограниченное применение в эколого-геологических исследования, будучи неограниченным ни снизу ни сверху.

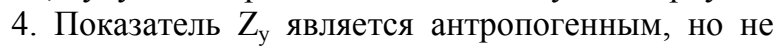
учитывает синергетическое взаимодействие ЗВ. Поэтому он ограничен только снизу, $Z_{\text {y } \min }=-3$, что соответствует уровню природного фона, не влияющего на здоровье человека. 


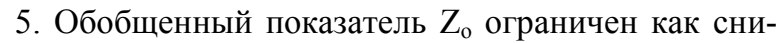
зу, так и сверху: $0 \leq Z_{\text {о }} \leq 4$, что связано с учетом синергетического взаимодействия ЗВ при достаточно высоких уровнях загрязнения окружающей среды. Он позволяет судить о влиянии загрязнения окружающей среды любым количеством ЗВ на комфортность проживания населения в различных регионах

\section{ЛИТЕРАТУРА}

1. Сает, Ю. Е. Геохимия окружающей среды / Ю. Е. Сает, Б. А. Ревич, Е. П. Янин. - М.: Недра, 1990. - 335 с.

2. Экологическая геология : практикум по специальности 020306 (013300)-экологическая геология / И. И. Косинова, О. В. Базарский, А. А. Панарин. - Воронеж : ЛОП ВГУ, 2005. $-88 \mathrm{c}$.

3. Комплексная оценка геосферы жизнедеятельности населения территории Липецкого промрайона : монография / И.

Военный учебно-научный центр военно-воздушных сил «Военно-воздушная академия имени профессора Н. Е. Жуковского и Ю. А. Гагарина», г. Воронеж

Базарский Олег Владимирович, профессор, доктор физикоматематических наук Тел.: 8 (473) 2208289

Воронежский государственный университет

Курышев Александр Александрович, кандидат геологоминералогических наук, доцент кафедры экологической геологии

E-mail:kaa@geol.vsu.ru

Тел.: 8 (473) 2208289
И. Косинова [и др.]- Воронеж : Воронежский государственный архитектурно-строительный университет, 2014. - 175 с. 4. Курышев, А. А. Методологические аспекты оценки суммарных воздействий загрязняющих веществ на компоненты природной среды / А. А. Курышев, А. Е. Косинов // Материалы научной сессии Воронежского государственного университета. Секция экологической геологии. - Воронеж, 2008. - C. 55-59.

5. Экологическая геология крупных горнодобывающих районов Северной Евразии (теория и практика) / под ред. И. И. Косиновой.- Воронеж, 2015.- С. 53-57.

6. Грибов, Л. А. Основы физики : учебник для студ. естеств.-науч. направлений вузов / Л. А. Грибов, Н. И. Прокофьева .- 2-е изд., доп. - М. : Физматлит, 1995. - 554 с.

7. Базарский, О. В. Математическое моделирование загрязнения приповерхностных отложений аэрозольными частицами / О. В. Базарский, И. И. Косинова, С. И. Фонова // Инженерные изыскания : всероссийский научноаналитический журнал. - Москва, 2015. - № 5-6. - С. 76-79.

Air Force Military Educational and Scientific Center "Air Force Academy named after Professor N. E. Zhukovsky and Y. A. Gagarin"

Bazarsky O. V., Professor, Doctor of Physical and Mathematical Sciences

Tel.: 8 (473) 2208289

Voronezh State University

Kuryshev A. A., Candidate of Geological and Mineralogical Sciences, Associate professor of Ecological Geology Department

E-mail:kaa@geol.vsu.ru

Tel.: 8 (473) 2208289 